\title{
THE EPIDEMIOLOGY OF GYNAECOLOGICAL DISORDERS IN GERIATRIC POPULATION: A HOSPITAL BASED STUDY.
}

Ramprasad Dey, Mriganka Mouli Saha, Abhijit Rakshit, Subhash Chandra Biswas,

Arunima Mukhopadhyay

1. Associate Professor. Department of Obstetrics \& Gynaecology, Bankura Sammilani Medical College.

2. Junior Resident. Department of Obstetrics \& Gynaecology, IPGMER, Kolkata.

3. Assistant Professor. Department of Obstetrics \& Gynaecology, IPGMER, Kolkata.

4. Professor. Department of Obstetrics \& Gynaecology, Burdwan Medical College,

5. Assistant Professor. Department of General Surgery, Calcutta National Medical College.

\section{CORRESPONDING AUTHOR:}

Dr. Ramprasad Dey,

836, Block - P. New Alipore,

Kolkata-700053.

E-mail: drrpdey@gmail.com ; ram_arunima@yahoo.co.in

ABSTRACT:OBJECTIVES: Geriatric gynaecology deals with gynaecological pathology encountered in postmenopausal women at and above 60 years of age with an intention of early diagnosis and management . A major challenge for the world in the 21st century is the ageing of its population. As the life expectancy of postmenopausal women has risen dramatically, hence this study was taken up to analyze incidence, diagnosis, treatment of gynaecological disorders in females aged 60 years and above. METHODS: It is an retrospective observational study of female patients aged 60 years and above, admitted in the department of Obstetrics and Gynaecology, IPGMER and SSKM Hospital, Kolkata over a period of one year. Data was collected from admission and OT register. Age distribution, spectrum of gynaecological disorder, type of surgeries performed, were noted and analyzed. RESULTS: In our study ninety patients were aged 60 years or more amongst total admission of 811 comprising age related incidence of $11.09 \%$. The mean average age of admission was 64.19 years. Uterovaginal prolapse(51.1\%) was the commonest clinical problem followed by malignancy (26.7\%). Among the gynaecological malignancies (24 patients) ovarian carcinoma was the most common (50\%) followed by endometrial carcinoma(33.3\%).Total 36 patients of uterovaginal prolapse were managed surgically. All patients of malignancy were treated surgically. Among Nine cases of stress urinary incontinence, seven managed by TVT/TOT. CONCLUSION: Uterovaginal prolapse and malignancy were the major gynaecological problems in older women. In future geriatric gynaecology will play an important role in India, as the size of elderly population is increasing over time.

KEY WORDS: Geriatric population, Geriatric gynaecological disorders.

INTRODUCTION: Geriatric gynaecology deals with gynaecological pathological conditions encountered in postmenopausal women at and above 60 years of age with an intention of early diagnosis and management of those conditions and to create a sense of wellbeing1.With the development in the field of medicine and better control over communicable and chronic diseases, there is a decreasing trend in mortality in adults and hence the life expectancy in Indian females has risen from 31.7 years in 1941 to 64.2 years in 20062. The number of women aged above 60 years has grown from 5.4\% in 1951 to $7.8 \%$ in 20013. It is projected to rise to $12.4 \%$ of population by the year 20262 . The Indian society which was pyramidal till 20th 
century, has become rectangular today and morbidity related geriatric gynaecological problems are on rise. According to official population projections, the number of elderly persons will rise to approximately 140 million by $2021 \&$ there will be approximately 130 million elderly women in India by the year 20152,4.Hence this study was taken up to analyze incidence, diagnosis, treatment of gynaecological disorders in females aged 60 years and above.

MATERIALS AND METHODS: It is a retrospective observational study of female patients aged 60 years and above admitted in the department of Obstetrics and Gynaecology, IPGMER and SSKM Hospital, Kolkata over a period of 1 year (February 2011 to January 2012). Data was collected from admission and OT register of our department. 90 patients were aged 60 years or more amongst total admission of 811 comprising incidence of $11.09 \%$. The mean average age of admission was 64.19 years. Age distribution, spectrum of gynaecological disorder, type of surgeries performed were noted and analyzed.

RESULTS: In our study ninety patients were aged 60 years or more amongst total admission of 811 comprising incidence of $11.09 \%$. The mean average age of admission was 64.19 years .As shown in Table 1, 41 (45.56\%) of them were between 60 to 65 years of age group, 21(23.33\%) were between the age of 65 to 70 years. Twenty (22.22\%) of them were between 70 to 75 years of age and only eight (8.89\%) women were above 75 years of age. The maximum age of a patient was 84 years, who presented with stress urinary incontinence. Uterovaginal prolapse $(51.1 \%)$ was the commonest problem followed by genital malignancy (26.7\%) [Table 2]. Among the gynaecological malignancies (24 patients), ovarian carcinoma was the most common (50\%) followed by endometrial carcinoma(33.3\%)[Table 2]. All patients of malignancy were treated surgically. Out of total 46 women who presented with uterovaginal prolapse, 36 were managed surgically. Among them 30 women underwent Ward Mayo's operation, four underwent Sacrospinous fixation along with Ward Mayo's operation \& two underwent Sacrocolpopexy [Table 4].Only three patient were admitted for benign abdominal lump \& two were admitted due to post operative complications. Among the total 15 urinary incontinence patients, nine cases were diagnosed as stress urinary incontinence \& seven of them managed by TVT/TOT, two of them underwent Burch colpo-suspension[Table 5].Remaining six patients of urinary incontinence suffering from overactive bladder(OAB) \& urge incontinence, were managed conservatively.

DISCUSSION \& CONCLUSION: In our study, the most common gynaecological disorder was uterovaginal prolapse (51.1\%), followed by genital malignancy $(26.7 \%)$, the second most common. Among the gynaecological malignancies (24 patients), ovarian carcinoma was the most common(50\%) followed by endometrial carcinoma(33.3\%).Only two women had cervical carcinoma and the same number of patients had carcinoma vulva. All the cases of ovarian malignancies $(n=12)$ were treated with total abdominal hysterectomy with bilateral salpingooophorectomy and infracolic omentectomy (Table 3). Out of the eight patients with endometrial carcinoma, three had early stage(stage IA) and hence underwent TAH(Extrafascial) with BSO and rest of them(five) had advanced stage carcinoma and as a result of that Type 2 radical hysterectomy or Wertheim's hysterectomy were done. Both the women with carcinoma cervix had stage IIA and Wertheim's hysterectomy was done for both the cases. Both the cases of carcinoma vulva had undergone Radical vulvectomy with bilateral inguinofemoral lymphadenectomy As cervical malignancy usually presents at a younger age, there is a relatively 
lower incidence of cervical malignancy in our study of geriatric patients. Further the cervical cancer screening programme has contributed to the reduced incidence of cervical cancer in the study population. Prior to the screening programme, 30\% women with Postmenopausal bleeding had an underlying malignancy, of which one third were cervical cancers. The scenario depicted in our study resembles that of the Sweden study prior to cervical cancer screening5.According to the Indian cancer registry, there is an increasing trend for ovarian and corpus uteri malignancies in the past two decades6. This was similarly observed in our study where carcinoma of the ovary and endometrium were the common malignancies.

Pelvic floor dysfunction is a major health issue for older women, and the likelihood of undergoing an operation for pelvic organ prolapse by the age of 80 years is $11 \% 7$. Uterovaginal prolapse was the commonest problem. In our study, total 46 women $(51.1 \%)$ had uterovaginal prolapse. The lion share of them i.e. 39 had second degree prolapse, whereas only three of them had first degree prolapse and two patient each had procidentia and vault prolapse. Out of these 46 patients, 42 of them i.e. $91.30 \%$ had associated cystocele, rectocele or enterocele. Among those with uterovaginal prolapse, 36 women were managed surgically. Thirty women had undergone Ward Mayo's operation, four underwent Sacrospinous fixation along with Ward Mayo's operation. Both the women with vault prolapse were managed by Sacrocolpopexy. Oslen AL et al showed in their study that the age-specific incidence of genital prolapse increased with advancing age \& most patients were older, postmenopausal, parous, and overweight7.This was similarly found in our study. Moreover, in our study we have only taken gynaecological indoor patient into consideration and that is why there was not a single case of senile vaginitis or endometritis. The pelvic floor plays a very important role in pelvic organ support. Obstetrician may be able to reduce pelvic floor injuries by minimizing unnecessary forceps deliveries by allowing passive descent in the second stage, and by selectively recommending elective caesarean delivery. Postmenopausal estrogen replacement therapy may reduce the incidence of prolapse 8 .

Only three women above 60 years of age were admitted for benign abdominal lump. Among them two patients presented with ovarian cyst and one with endometrial hyperplasia (without atypia). All of them were managed by TAH with BSO. Out of the total ninety admissions only two were due to post operative complications. One of them developed wound infection following radical hysterectomy done in a private hospital. She was managed conservatively with intravenous antibiotics. The other woman had developed pelvic infection following vaginal hysterectomy \& managed conservatively.

A total 15 women got admitted with urinary incontinence. Among them nine women presented with stress urinary incontinence (SUI). Five of them were managed by "TOT"(trans obturator tape) and two of them with "TVT-0"( tension free vaginal tape - obturator). Rest of the two women underwent Burch's colposuspension. Stress urinary incontinence (SUI) has a significant impact on the quality of life for many women. Most women do not seek medical attention for this condition. The gold-standard surgical treatment of SUI in patients with a mobile bladder neck and normally functioning urethra has been accomplished through a retropubic approach using either a Burch or Marshall-Marchetti-Krantz procedure. By the absolute success of trans obturator tape (TOT) application in treatment of SUI, it seems to be little doubt that TOT has became the new gold Standard for treatment of SUI in recent times9.

To conclude, pelvic organ prolapse and malignancy were the major gynaecological problems in older women above 60 years. General practitioners who interact with women during menopause may play a great role by entering them into regular health care system, maintenance 
of continuity of care and can screen patients who require appropriate consultant's opinion. Patient's awareness and education can also play a major role. A thorough pelvic examination should be done in all geriatric women periodically in order to detect and treat the malignancies at the earliest and to decrease the incidence of advanced cancer and related morbidity and mortality.

In future, geriatric gynaecology will play an important role in India, as the size of elderly population is increasing over time.

\section{REFERENCES:}

1. Takkar N,Goel P,Dua D,Mohan H,Huria A,Sehgal A. Spectrum of gynaecological disorders in older Indian women: a hospital based study. Asian J Gerontol Geriatr 2010; 5: 69-73.

2. Situation Analysis of The Elderly in India. Central Statistics Office ,Ministry of Statistics \& Programme Implementation. Government of India. c2011 - [cited 2011 June]. Available from: http://mospi.nic.in/mospi_new/upload/elderly_in_india.pdf ,accessed on 6 April 2011.

3. Censusindia.gov.in. New Delhi: Census of India. c2001. Available from: http://www.censusindia.gov.in/Census_Data_2001/India_at_glance/broad.aspx, accessed on April 5, 2011.

4. Kaulagekar A. Menopause and Femininity: Qualitative Enquiry into Menopause of Urban Women from Pune, Maharashtra. Anthropologist 2010; 12(1): 23-26.

5. Gredmark T, Kvint S, Havel G, Mattsson LA. Histopathological findings in women with postmenopausal bleeding. Br J Obstet Gynaecol. 1995; 102(2):133-6.

6. Yeole BB. Trends in cancer incidence in female breast, cervix uteri, corpus uteri, and ovary in India. Asian Pac J Cancer Prev 2008; 9:119-22.

7. Oslen AL, Smith VJ, Bergstrom JO, Colling JC, Clark AL. Epidemiology of surgically managed pelvic organ prolapse and urinary incontinence. Obstet Gynecol 1997; 89:5016.

8. Handa VL, Harris TA, Oestergard DR. Protecting the pelvic floor: Obstetric managementto prevent incontinence and pelvic organ prolapse. Obstet Gynecol 1996; 3 : 470-80. Magon N, Kalra B, Malik S, Chauhan M. Stress urinary incontinence: What, when, why, and then what?. J Midlife Health. 2011 ; 2(2):57-64.

Table 1: Age distribution of elderly women (study population)[n=90]

\begin{tabular}{|l|l|l|}
\hline Age (in years) & Number & Incidence $\%$ \\
\hline $60-65$ & 41 & 45.56 \\
\hline $65-70$ & 21 & 23.33 \\
\hline $70-75$ & 20 & 22.22 \\
\hline$>75$ & 08 & 8.89 \\
\hline
\end{tabular}


Table 2: Spectrum of gynaecological disorders in elderly women $(n=90)$

\begin{tabular}{|c|c|c|c|}
\hline \multicolumn{2}{|l|}{ Disease } & Number & Overall Incidence \% \\
\hline \multirow{4}{*}{$\begin{array}{l}\text { Uterovaginal prolapse } \\
(\mathrm{n}=46) \\
51.11 \%\end{array}$} & First degree prolapsed & 3 & 3.33 \\
\hline & Second degree prolapsed & 39 & 43.33 \\
\hline & Procidentia & 2 & 2.22 \\
\hline & Vault prolapsed & 2 & 2.22 \\
\hline \multirow{4}{*}{$\begin{array}{l}\text { Malignancies } \\
(n=24) \\
26.67 \%\end{array}$} & Cervical carcinoma & 2 & 2.22 \\
\hline & Endometrial carcinoma & 8 & 8.89 \\
\hline & Ovarian carcinoma & 12 & 13.33 \\
\hline & Vulval carcinoma & 2 & 2.22 \\
\hline Urinary incontinence & & 15 & 16.67 \\
\hline \multirow{2}{*}{$\begin{array}{ll}\text { Benign } & \text { abdominal } \\
\operatorname{lump}(\mathrm{n}=3) & \\
3.33 \% & \end{array}$} & Benign Ovarian lesion & 2 & 2.22 \\
\hline & $\begin{array}{ll}\text { Endometrial } & \text { hyperplasia } \\
\text { (without atypia) } & \end{array}$ & 1 & 1.11 \\
\hline \multirow{2}{*}{$\begin{array}{l}\text { Other conditions } \\
(\mathrm{n}=2) \\
2.22 \%\end{array}$} & $\begin{array}{l}\text { Post Radical hysterectomy } \\
\text { wound infection }\end{array}$ & 1 & 1.11 \\
\hline & $\begin{array}{l}\text { Post Ward Mayo operation } \\
\text { pelvic floor infection }\end{array}$ & 1 & 1.11 \\
\hline
\end{tabular}

Table 3: Types of surgeries performed in gynaecological malignancy [n=24]

\begin{tabular}{|l|l|l|}
\hline Type of surgery & Number & Percentage(\%) \\
\hline TAH with BSO + infracolic omentectomy & 12 & 50 \\
\hline TAH(Extrafascial) with BSO & 3 & 12.5 \\
\hline Wertheim's hysterectomy & 7 & 29.17 \\
\hline Radical vulvectomy & 2 & 8.33 \\
\hline
\end{tabular}

* TAH with BSO - Total abdominal hysterectomy with bilateral salpingo-oophorectomy .

Table 4: Types of surgeries for uterovaginal prolapse[n=36]

\begin{tabular}{|l|l|l|}
\hline Types of surgery & Number & Percentage(\%) \\
\hline Ward Mayo's operation & 30 & 82.35 \\
\hline Ward Mayo's operation + Sacrospinous fixation & 4 & 11.77 \\
\hline Sacrocolpopexy & 2 & 5.88 \\
\hline
\end{tabular}

Table 5: Types of surgeries for SUI [total case $=9]$

\begin{tabular}{|l|l|}
\hline Types of surgery & Number \\
\hline TOT* & 5 \\
\hline TVT $-0^{* *}$ & 2 \\
\hline Burch colposuspension & 2 \\
\hline
\end{tabular}

*Trans obturator tape ${ }^{* *}$ Tension free vaginal tape - obturator 